\title{
From the Editor-in-Chief
}

\author{
Kimon P. Valavanis
}

Published online: 13 November 2010

(c) Springer Science+Business Media B.V. 2010

\section{Dear Colleagues,}

For the last three years we publish an annual Special Volume devoted to Unmanned Aircraft Systems (UAS), which includes enhanced versions of peer reviewed papers presented in our annual UAV conference - this has been the case for 2008, 2009 and 2010, with the Special Volumes appearing in January of 2009, 2010, 2011, respectively.

It is this idea I would like to focus on in this editorial: I encourage you to consider such special projects, particularly when it comes to cutting edge research and technology areas - UAS is not but one such area. The policy is the same as with regular papers. Every submission is peer reviewed. This way, quality is preserved, however, our journal will offer better service to our readership as it will publish first recent advances in specific fields. I encourage you to do so, or at least consider this possibility.

In the mean time, enjoy the issue.

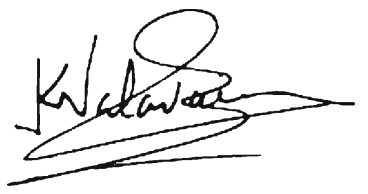

Kimon P. Valavanis

Editor-in-Chief

K. P. Valavanis $(\varangle)$

Journal of Intelligent and Robotic Systems,

Department of Electrical and Computer Engineering,

School of Engineering and Computer Science,

University of Denver, Denver, CO 80208, USA

e-mail:kvalavan@du.edu 